\title{
Hubungan Labilitas/ Negativitas Dan Regulasi Emosi Dengan Derajat Kesulitan Belajar Anak ADHD Di RSUD Dr. Soetomo Surabaya
}

\author{
Correlationbetweenlability/ Negativity And Emotional Regulationwith The \\ Degree Of Learning Difficulties On Children With Adhdat RSUD Dr. \\ Soetomo Surabaya
}

Oleh:

HESTY NOVITASARI*

LESTARI BASOEKI**

\footnotetext{
* Dokter umum, peserta PPDS I Psikiatri Departemen/ SMF Ilmu Kedokteran Jiwa FK Universitas Airlangga/ RSUD Dr. Soetomo Surabaya, alamat korespondensi: Jl. Siwalankerto no. 47 Surabaya, email: Hestybundanania@gmail.com. No. HP: 081230822700

**Guru Besar, Dokter Spesialis Kedokteran Jiwa/ Psikiater (Konsultan), Staf Pengajar Departemen/ SMF Ilmu Kedokteran Jiwa FK Universitas Airlangga/ RSUD Dr. Soetomo Surabaya
} 


\begin{abstract}
ABSTRAK
Latar Belakang:Prevalensi $A D H D$ meningkat tajam, anak $A D H D$ umumnya mengalami labilitas/ negativitas emosi buruk, terjadi selama hidupnya. Mereka cenderung menunjukkan emosi lebih tinggi dibandingkan anak normal, karena keterbatasan kapasitas dalam menghambat respon emosional mereka. Dalam bidang akademis, anak dengan $A D H D$ menunjukkan prestasi akademik rendah. Hal ini karena kurangnya perhatian, impulsivitas, ketidakmampuan mengorganisasi aktivitasnya, sehingga sering mengalami kesulitan belajar. Guru dan orangtua sering mengeluhkan emosi anak $A D H D$, sedangkan teman-temannya cenderung menghindari bergaul dengannya. Hal ini menyebabkan regulasi emosi negatif yang berdampak terhadap proses belajarnya.

Tujuan:Mengidentifikasi hubungan labilitas/ negativitas dan regulasi emosi dengan derajat kesulitan belajar anak $A D H D$ di RSUD Dr. Soetomo Surabaya.

Metode:Studi analitik observasional, desain cross sectional, dengan teknik consecutive sampling. Instrumen penelitian menggunakan Skala Penilaian Perilaku Anak Hiperaktif Indonesia (SPPAHI), Emotion Regulation Checklist (ERC) dan Colorado Learning Difficulties Questionnaire (CLDQ).

Hasil:Didapatkan 30 subyek penelitian. Uji analisis statistik menyatakan terdapat hubungan yang bermakna antara subskala labilitas/ negativitas maupun regulasi emosi dengan derajat kesulitan belajar anak $A D H D$. Terdapat juga hubungan yang bermakna antara subskala labilitas/ negativitas maupun regulasi emosi dengan derajat kesulitan belajar pada domain social cognition dan spatial difficulties.Simpulan:Terdapat hubungan antara subskala labilitas/negativitas maupun regulasi emosi dengan derajat kesulitan belajar.
\end{abstract}

Kata kunci: $A D H D$, labilitas/ negativitas, regulasi emosi, kesulitan belajar

\title{
ABSTRACT
}

Background:The prevalence of ADHD increased sharply, children with ADHD generally experience bad emotion lability/ negativity that occurs during their lifetime. They tend to show higher emotion than to the normal children, due to limited capacity in inhibiting their emotional responses. In the academic field, children with ADHD showed lower academic achievement. It is because of the lack of attention, impulsivity, inability to organize their activities, causing learning difficulties. Teachers and parents often complain about emotion in children with ADHD, and their friend tend avoid to interaction with him/ her. This can cause negative emotional regulation that will ultimately impact to the learning process.

Objective:To identify the correlation between the lability/ negativity and emotion regulation with the degree of learning difficulties in children with ADHD in Hospital Dr. Soetomo Surabaya.

Methods:The study was observational analytic, cross-sectional design, with consecutive sampling technique. The instrument used are Child Behavior Hyperactivity Scale Appraisal Indonesia (SPPAHI), Emotion Regulation Checklist (ERC) and the Colorado Learning Difficulties Questionnaire $(C L D Q)$.Results:There were 30 subjects. The statistical analysis show that there was a significant correlation between lability/ negativity and emotional regulation subscale with the degree of learning difficulties in children with ADHD. The statistically analyzed showed a significant correlation between the lability/ negativity and emotional regulation subscale with the degree of learning difficulties in the domain of social cognition and spatial difficulties.

Conclusions:There is a correlation between lability/ negativity and emotional regulation subscale with the degree of learning difficulties.

Keywords: $A D H D$, lability/negativity, emotion regulation, learning difficulties 


\section{PENDAHULUAN}

Attention Deficit and Hyperactivity Disorder (ADHD) atau Gangguan Pemusatan Perhatian dan Hiperaktivitas (GPPH) adalah suatu gangguan perilaku yang ditandai dengan gangguan pemusatan perhatian, impulsivitas dan disertai aktivitas berlebihan yang tidak sesuai dengan usianya, terdapat secara persisten/ menetap (APA 2013; KEMENKES 2011; Sadock \& Sadock 2007). Prevalensi ADHD telah meningkat tajam selama periode satu dekade di Amerika Serikat. Data terbaru menunjukkan bahwa $86 \%$ anak-anak dengan $A D H D$ digambarkan memiliki gangguan ringan atau sedang, dan beberapa didiagnosis tanpa memenuhi kriteria diagnosis untuk $A D H D$. Sesuai dengan kriteria DSM IV, prevalensi penderita gangguan ini pada anak usia sekolah sebesar 15,8\% di antara 3006 anak berusia 3 - 18 tahun. Pineda et al. (1999) melaporkan prevalensi gangguan ini terhadap 540 anak berusia 4 - 17 tahun diColumbia sebesar 18,2\% untuk anak usia prasekolah, 22,5\% untuk anak usia 6 -11 tahun dan 7,3\% untuk anak usia 12 - 17 tahun (Saputro 2009). Salah satu penelitian yang dilakukan oleh Dwidjo Saputro (2009) pada anak usia sekolah dasar di DKI Jakarta didapatkan angka prevalensi sekitar 26,2\%. Salah satu data dari unit Psikiatri Anak RSUD Dr. Soetomo, melaporkan 72 kasus $A D H D$ pada tahun 2008 dan 103 kasus pada tahun 2009 (Saputro 2009).

Beberapa peneliti berpendapat bahwa anak dengan $A D H D$ umumnya mengalami labilitas atau negativitas emosi yang buruk, terjadi selama hidupnya dan merupakan penyumbang utama untuk mengalami gangguan. Mereka cenderung menunjukkan emosi yang lebih tinggi dibandingkan dengan anak yang normal, disebabkan karena keterbatasan kapasitas dalam menghambat respon emosional mereka (Shaw et al. 2014; Anastopoulos et al. 2011). Anak dengan ADHD cenderung menunjukkan perhatian dan gairah yang berlebihan terhadap imbalan dan tampak sangat jelas mudah menjadi kecewa apabila penguat mulai berkurang, meskipun kondisi ini menunjukkan bahwa terdapat kesulitan dalam regulasi emosi pada anak $A D H D$, tetapi kemampuannya memahami emosi anak lain sama dengan anak normal (Saputro 2009). Dalam bidang akademis, anak dengan $A D H D$ menunjukkan prestasi akademik yang lebih rendah daripada prestasi optimal yang seharusnya dapat dicapainya. Mereka tidak bisa menerima materi pelajaran dengan baik karena kurangnya perhatian, impulsivitas, ketidakmampuan mengorganisasi aktivitasnya, sehingga sering mengalami kesulitan belajar dan gagal menyelesaikan tugas atau pekerjaan rumah. Kesulitan belajar ditemukan pada 10-25\% pada anak dengan ADHD. Guru dan orangtua seringkali mengeluhkan emosi anak dengan $A D H D$ ini, teman-temannya cenderung menghindari bergaul dengan anak yang mengalami $A D H D$, yang akibatnya mereka akan semakin mengalami regulasi emosi negatif seperti kehilangan rasa percaya diri, menarik diri dan depresi yang pada akhirnya akan berdampak pula terhadap proses belajarnya (Pastor \& Reuben 2008; Maag \& Reid 2006; Hallahan et al. 2005; AACAP 2002). 


\section{METODOLOGI PENELITIAN}

Penelitian ini merupakan penelitian analitik observasional yang bersifat cross sectional, untuk menganalisa hubungan labilitas/ negativitas emosi dengan derajat kesulitan belajar anak $A D H D$ di RSUD Dr. Soetomo Surabaya. Subyek penelitian adalah anak dengan ADHD yang memenuhi kriteria inklusi: Anak: anak dengan ADHD (F90) berdasarkan diagnosis yang tercantum pada rekam medis yang ditegakkan oleh Psikiater anak dengan berpedoman pada PPDGJ-III, rentang usia antara 6 - 11 tahun, tingkat IQ > 90 (menurut pemeriksaan pada anak ADHD yang baru berkunjung pertama kali), derajat $A D H D$ yang dipilih adalah skor SPPAHI sangat ringan (23 43), ringan (44 - 64), dan sedang (65 -84), serta Pengasuh Utama: orangtua kandung maupun orang lain yang mengasuh, tinggal dengan anak lebih dari 6 bulan, berpendidikan minimal lulus SD, bisa berbahasa Indonesia atau bahasa Jawa (lisan/ tulisan), bersedia mengikuti penelitian, sudah menyetujui maupun menandatangani informed consent/ lembar persetujuan menjadi responden yang diberikan sebelum penelitian. Kriteria ekslusi: Anak: adanya gangguan penglihatan, pendengaran, fraktur, lumpuh, gagap pada subyek penelitian yang diketahui dari rekam medis atau pemeriksaan fisik, serta Pengasuh Utama: kondisi psikotik, depresi berat secara klinis, dan komorbid dengan gangguan jiwa lain (berdasarkan saat wawancara). Digunakan kuesioner Skala Penilai Perilaku Anak Hiperaktif Indonesia (SPPAHI), Emotion Regulation Checklist (ERC), dan Colorado Learning Difficulties Questionnaire (CLDQ).

\section{HASIL PENELITIAN}

Data berdistribusi normal maka uji statistik menggunakan korelasi pearson. Jumlah subyek penelitian sebanyak 30 orang, jumlah tersebut masih memenuhi kriteria jumlah sampel minimal yang bisa dipakai dalam penelitian. Tabel 1. Karakteristik subyek penelitian (anak ADHD)

\begin{tabular}{|lcc|}
\hline \multicolumn{1}{c}{ Variabel } & Jumlah (N=30) & Persentase (\%) \\
\hline Usia Anak & & \\
6 & $\mathbf{1 1}$ & $\mathbf{3 6 , 7}$ \\
7 & 4 & 13,3 \\
8 & 4 & 13,3 \\
9 & 4 & 13,3 \\
11 & 7 & 23,3 \\
\hline Jenis Kelamin Anak & & \\
Laki-laki & $\mathbf{2 5}$ & $\mathbf{8 3 , 3}$ \\
Perempuan & 5 & 16,7 \\
\hline Pendidikan Anak & & \\
SD & $\mathbf{1 9}$ & $\mathbf{6 3 , 3}$ \\
TK & 11 & 36,7 \\
\hline Korban Bullying & & \\
Tidak & 10 & 33.3 \\
Ya & $\mathbf{2 0}$ & $\mathbf{6 6 , 7}$ \\
\hline Intelegensi & & \\
Atas & 10 & 33 \\
Bawah & $\mathbf{2 0}$ & $\mathbf{6 7}$ \\
\hline Lama terapi (psikofarmaka \& nonpsikofarmaka) & & \\
$0-1$ bulan & 6 & 20 \\
> - 6 bulan & 11 & 36,67 \\
$>$ 6 bulan - 5 tahun & $\mathbf{1 3}$ & $\mathbf{4 3 , 3 3}$ \\
\hline
\end{tabular}


Tabel 2. Distribusi data labilitas/ negativitas dan regulasi emosi anak $A D H D$ dari subyek penelitian

\begin{tabular}{|l|c|c|c|c|c|}
\hline \multicolumn{1}{|c|}{$\begin{array}{c}\text { Subskala } \\
\text { (rentang skor) }\end{array}$} & $\mathbf{N}$ & Minimum & Maksimum & Rerata & $\begin{array}{c}\text { Median } \\
\text { instrumen } \text { ERC }\end{array}$ \\
\hline Labilitas/ negativitas (16-64) & 30 & 16 & 50 & 33,07 & 34,00 \\
\hline Regulasi emosi (8-32) & 30 & 19 & 30 & 25,93 & 26,00 \\
\hline
\end{tabular}

Tabel 3. Distribusi data derajat kesulitan belajar anak $A D H D$ dari subyek penelitian

\begin{tabular}{|l|c|c|c|c|c|}
\hline \multicolumn{1}{|c|}{$\begin{array}{c}\text { Setiap domain CLDQ } \\
\text { (rentang skor) }\end{array}$} & N & Minimum & Maksimum & Rerata & $\begin{array}{c}\text { Median } \\
\text { instrumen } \\
\text { CLDQ } \boldsymbol{Q}\end{array}$ \\
\hline $\begin{array}{l}\text { DOMAIN : } \\
\text { Reading (6-30) }\end{array}$ & 30 & 6 & 27 & 14,00 & 18 \\
\hline Social cognition (4-20) & 30 & 4 & 16 & 8,83 & 12 \\
\hline Social anxiety (3-15) & 30 & 3 & 13 & 5,57 & 9 \\
\hline Spatial difficulties (4-20) & 30 & 4 & 20 & 11,47 & 12 \\
\hline Math (3-15) & 30 & 3 & 15 & 7,97 & 9 \\
\hline $\begin{array}{l}\text { Keseluruhan domain } \\
\text { CLDQ(20-100) }\end{array}$ & 30 & 24 & 72 & 47,83 & 60 \\
\hline
\end{tabular}

Tabel 4. Hubungan labilitas/ negativitas maupun regulasi emosi dengan derajat kesulitan belajar anak $A D H D$ dari subyek penelitian

\begin{tabular}{|l|c|c|}
\hline \multirow{2}{*}{ Variabel } & \multicolumn{2}{|c|}{ Derajat kesulitan belajar } \\
\cline { 2 - 3 } & $\mathbf{R}$ & $\mathbf{P}$ \\
\hline Labilitas/ negativitas & 0,39 & $\mathbf{0 , 0 3}$ \\
\hline Regulasi emosi & $-0,43$ & $\mathbf{0 , 0 2}$ \\
\hline
\end{tabular}

Tabel 5. Hubungan labilitas/ negativitas maupun regulasi emosi dengan setiap domain dari derajat kesulitan belajar anak ADHD dari subyek penelitian

\begin{tabular}{|l|c|c|}
\hline \multicolumn{1}{|c|}{ Variabel } & Labilitas/ negativitas emosi & Regulasi emosi \\
\hline Reading & r: $-0,07$ & r: $-0,16$ \\
& p: 0,72 & p: 0,40 \\
\hline Social cognition & r: 0,57 & r: $-0,36$ \\
Social anxiety & p: $\mathbf{0 , 0 0 1}$ & p: $\mathbf{0 , 0 5}$ \\
& r: 0,33 & r: 0,12 \\
Spatial difficulties & p: 0,07 & p: 0,51 \\
\hline Math & r: 0,43 & r: $-0,56$ \\
& p: $\mathbf{0 , 0 2}$ & p: $\mathbf{0 , 0 0 1}$ \\
\hline
\end{tabular}




\section{DISKUSI}

Pada subskala labilitas/ negativitas emosi (tabel 2), subyek penelitian mempunyai labilitas/ negativitas emosi yang rendah. Hasil penelitian ini tidak berbeda dengan penelitian sebelumnya yang dilakukan oleh Anastopoulos et al. (2011) terhadap anak ADHD, didapatkan sebagian besar $(53,08 \%)$ mengalami labilitas/ negativitas emosi yang rendah. Untuk subskala regulasi emosi, subyek penelitian menunjukkan regulasi emosi yang tinggi. Dalam penelitian ini hal tersebut dianggap subyek penelitian mempunyai regulasi emosi yang baik. Hasil penelitian ini sesuai dengan penelitian sebelumnya yang dilakukan oleh Wrong (2008) terhadap anak $A D H D$, dimana didapatkan hanya 10-19\% menunjukkan disregulasi emosi, sedangkan sebagian besar anak menunjukkan regulasi emosi yang baik (81-90\%). Dari studi kepustakaan Bonanno \& Mayne (2001) dalam tulisannya yang berjudul "Emotion: Current Issues and Future Directions" dijelaskan bahwa kemampuan resiliensi yang dimiliki oleh orangtua akan menghasilkan kemampuan orangtua dalam meregulasi emosinya dengan baik. Hal ini akan berdampak positif karena mereka memiliki reaksi emosional yang positif dan akan mengontrol emosi dengan cara menghambat keluarnya tanda-tanda emosi yang bersifat negatif. Dengan demikian orangtua khususnya ibu atau pengasuh utama dapat mengatasi dan beradaptasi terhadap masalah untuk mengatasi perilaku anak $A D H D$ yang agresif dan mengubah pikiran atau penilaian tentang situasi untuk menurunkan dampak emosional, sehingga menghasilkan reaksi emosional yang positif. Selain itu dapat memotivasi ibu untuk membimbing anaknya mengalami perubahan positif yang optimal pada diri anak. Pada penelitian ini jumlah subyek penelitian lama lebih banyak dibanding yang baru (tabel 1), yang mana subyek penelitian lama sudah mendapat intervensi baik psikofarmaka maupun non psikofarmaka. Selama subyek penelitian menjalani terapi di RSUD Dr. Soetomo, pengasuh utama mendapat psikoedukasi mengenai pengasuhan anaknya secara benar dan positif, hal ini memungkinkan untuk terjadinya perubahan yang positif dan optimal pada diri anak dan pada akhirnya membuat subyek penelitian mempunyai regulasi emosi yang baik.Hal ini sesuai dengan kepustakaan Bonanno \& Mayne (2001) yang menyatakan bahwa pengasuhan yang baik akan membuat regulasi emosi yang baik pada anak. Jadi regulasi emosi anak itu tidak semata-mata dipengaruhi oleh kondisi ADHD-nya, tetapi masih banyak faktorfaktor yang berpengaruh terhadap reaksi emosi anak, salah satunya adalah kemampuan resiliensi yang dimiliki orangtua/ pengasuh utama, sedangkan dalam penelitian ini peneliti tidak mengevaluasi kemampuan regulasi emosi pengasuh utama dari subyek penelitian, yang sebenarnya merupakan variabel perancu.

Derajat kesulitan belajar keseluruhan domain pada subyek penelitian ini menunjukkan derajat kesulitan belajar yang rendah. Hasil penelitian ini berbeda dengan berbagai penelitian sebelumnya yang dilakukan oleh Smith \& Adams (2006) dan Carmichael et al. (1997) yang menemukan bahwa 41-80\% dari anak ADHD mengalami derajat kesulitan belajar yang tinggi. Perbedaan ini kemungkinan besar disebabkan karena subyek dalam penelitian ini mempunyai intelegensi yang cukup baik (rata-rata 97,50); data demografi SPPAHI hanya dalam derajat yang sangat ringan, ringan, 
dan sedang. Kemungkinan juga masih banyak faktor-faktor perancu lainnya yang tidak terkendalikan. Apabila dilihat dari data derajat kesulitan belajar (tabel 3), dari literatur yang ada, tidak ada yang membahas secara rinci untuk setiap domainnya, namun ada literatur yang menyebutkan bahwa kesulitan belajar pada anak $A D H D$ terutama pada domain reading, social cognition dan spatial difficulties (Willcutt et al. 2011; Smith \& Adams 2006; Maag \& Reid 2006).

Dalam penelitian ini didapatkan adanya hubungan yang bermakna antara subskala labilitas/ negativitas maupun regulasi emosi dengan derajat kesulitan belajar anak $A D H D$ dari subyek penelitian. Hal ini sesuai dengan hasil penelitian sebelumnya yang dilakukan oleh Fox \& Calkins (2013) yang ditulis dalam laporan hasil penelitian dari Rush (2014), Hoza (2007), dan Palombo (2001) membuktikan adanya hubungan regulasi emosi (secara total) dengan derajat kesulitan belajar. Begitu juga setelah dianalisa secara statistik hubungan antara subskala labilitas/ negativitas serta regulasi emosi dengan setiap domain derajat kesulitan belajar ternyata menunjukkan adanya hubungan yang bermakna pada domain social cognition dan spatial difficulties. Untuk domain social cognition, didukung oleh pernyataan Blair dalam tulisannya tentang School Readiness (2002) yang menyebutkan bahwa pada studi hubungan antara kognisi dan emosi didapatkan peran emosi untuk mengorganisasi maupun mengarahkan kognisi dan juga pengembangan maupun integritas dari fungsi kognitif eksekutif. Penggunaan dan otomatisasi kemampuan fungsi eksekutif sangat tergantung pada interaksi timbal balik dari pikiran dan pusat emosi dari fungsi otak. Terkait dengan hal ini minimal terdapat dua implikasi penting untuk kesiapan sekolah, yang pertama adalah bayi dan balita yang ditandai dengan tingginya emosi negatif, sehingga berisiko tinggi untuk ketidaksiapan sekolah. Yang kedua adalah lingkungan rumah dan pendidikan prasekolah yang dirancang khusus untuk mengurangi stres dan menumbuhkan kompetensi emosional yang seharusnya membutuhkan perhatian dan pengaturan kognitif untuk adaptasi sosial dan kognisi terhadap teman-teman sekelas. Sebagian besar peneliti (Keenan \& Shaw 2003; Calkins 1997; Garber \& Dodge 1991) menyatakan bahwa regulasi emosi berupaya untuk memodulasi rangsangan emosional dengan cara memfasilitasi fungsi adaptif yang mengacu pada berbagai hasil positif global termasuk normatif sosial, kognitif, dan perkembangan bahasa serta kemampuan untuk mengatasi tugas-tugas sehari-hari dan perubahan lingkungan. Pada anak-anak, fungsi akademik adalah komponen penting dari fungsi adaptif(Kamphaus 1987).

Domain spatial difficulties dari kesulitan belajar menunjukkan ada hubungan yang bermakna dengan subskala labilitas/ negativitas dan regulasi emosi. Hal ini didukung oleh kepustakaan Gray, Braver \& Raichle (2002) yang menjelaskan bahwa keadaan emosi yang tidak menyenangkan mengganggu memori kerja verbal namun memperbaiki memori kerja spasial. Efek yang menyenangkan menghasilkan pola yang berlawanan (memori kerja verbal yang lebih baik dan memori kerja spasial terganggu). 
Domain reading, social anxiety, dan math dari kesulitan belajar menunjukkan tidak adanya hubungan yang bermakna dengan subskala labilitas/ negativitas dan regulasi emosi. Hal ini kemungkinan disebabkan bahwa item kuesioner $C L D Q$ yang dipakai untuk menilai domain reading (kuesioner $C L D Q$ nomor 1-6) tidak secara detail mengevaluasi komponen-komponen kesulitan reading, sehingga tidak sesuai dengan bentuk-bentuk kesulitan reading di antaranya berupa: penambahan huruf pada suku kata (addition) misalnya: "gula" menjadi "gulka", penghilangan huruf (omission) misalnya: "kompor" menjadi "kopor", pembalikkan kiri-kanan (inversion) misalnya: "buku" menjadi "duku", pembalikkan atas-bawah (reversall) misalnya: "m" menjadi "w", dan penggantian (substitusi) misalnya: "mega" menjadi "meja" (Suryani 2010).

Untuk domain social anxiety menurut Henriques (2016) dijelaskan terdiri dari beberapa komponen kemampuan yaitu 1) emosi dan suasana hati, ketakutan dan kecemasan khususnya; 2) ciri kepribadian neurosis dan (low) extraversion; 3) motif terhadap nilai relasi dan pengaruh sosial; 4) jaminan attachment vs insecurity; 5) kecemasan tentang orang asing dan ketidakpastian, kinerja dan perbandingan, dan konflik dan penolakan; 6) sifat alami manusia dalam menyaring dirinya keluar; dan 7) peran narator internal, yang pada kecemasan sosial sering menjadi "introyeksi yang disadari, kritis", sering teraktivasi dalam situasi-situasi sosial yang baru. Pada penelitian ini kuesioner $C L D Q$ yang berhubungan dengan penilaian domain social anxiety hanya diwakili 3 pernyataan yang rasanya kurang mewakili ke-7 komponen tersebut, sehingga hasil penilaian menjadi kurang akurat. Hal ini kemungkinan sebagai penyebab analisa hubungan antara domain social anxiety secara tersendiri tidak menunjukkan hasil yang signifikan.

Demikian juga untuk item kuesioner $C L D Q$ yang menilai domain math (kuesioner $C L D Q$ nomor 18-20) hanya menilai secara umum dan kurang secara rinci mengeksplorasi kemampuankemampuan yang terkait dalam domain math, dari tingkat yang paling sederhana sampai kemampuan yang kompleks, yaitu: 1) kemampuan dasar seperti klasifikasi, komparasi, seriasi/ mengurutkan, simbolisasi, dan konservasi; 2) kemampuan dalam menentukan tempat; 3) kemampuan melakukan operasi penjumlahan dengan atau tanpa teknik menyimpan dan pengurangan dengan atau tanpa teknik meminjam; 4) kemampuan memahami konsep perkalian dan pembagian; serta 5) kemampuan menjumlah dan mengurang bilangan bulat (Suryani 2010).

\section{KETERBATASAN PENELITIAN}

Dalam penelitian ini peneliti menggunakan kuesioner Colorado Learning Difficulties Questionnaire $(C L D Q)$ yang diisi hanya oleh pengasuh utama melalui pengamatan di rumah, akan lebih baik apabila diteliti juga penilaian oleh guru di sekolah. Peneliti sudah mengupayakan untuk mengendalikan faktor-faktor perancu, namun masih perlu dioptimalkan, antara lain: pengendalian terhadap faktor psikologis seperti minat, bakat, motif serta faktor eksternal seperti keluarga terutama 
regulasi emosi pengasuh utama, sekolah dan masyarakat, dan juga lama terapi subyek penelitian hanya didata saja, tidak dihitung.

\section{SIMPULAN}

Subyek penelitian menunjukkan labilitas/ negativitas emosi yang rendah, dan regulasi emosi yang tinggi (baik). Rata-rata subyek penelitian menunjukkan derajat kesulitan belajar rendah, baik mengenai kesulitan belajar keseluruhan domain maupun terkait dengan setiap domainnya yaitu domain reading, social cognition, social anxiety, spatial difficulties, dan math.

Adanya hubungan yang bermakna antara labilitas/ negativitas emosi dengan derajat kesulitan belajar dalam arti makin tinggi labilitas/ negativitas emosi maka makin tinggi derajat kesulitan belajar. Antara regulasi emosi dengan derajat kesulitan belajar didapatkan adanya hubungan terbalik yang bermakna dalam arti makin tinggi regulasi emosi maka makin rendah derajat kesulitan belajarnya. Adanya hubungan yang bermakna antara labilitas/ negativitas serta regulasi emosi terkait dengan derajat kesulitan belajar pada domain social cognition dan spatial difficulties dalam arti makin tinggi labilitas/ negativitas emosi maka makin tinggi derajat kesulitan belajar pada domain social cognition dan spatial difficulties. Antara subskala regulasi emosi dengan derajat kesulitan belajar didapatkan adanya hubungan terbalik yang bermakna dalam arti makin tinggi regulasi emosi maka makin rendah derajat kesulitan belajar domain social cognition dan spatial difficulties-nya. Untuk domain reading, social anxiety, dan math dari kesulitan belajar tidak menunjukkan adanya hubungan baik dengan subskala labilitas/ negativitas maupun regulasi emosi.

\section{DAFTAR PUSTAKA}

Anastopoulos, AD, Smith, TF, Garrett, ME, Morrissey-Kane, E, Schatz, NK, Sommer, JL, Kollins, SH \& Ashley-Koch, A 2011, "Self-Regulation of Emotion, Functional Impairment, and Comorbidity Among Children With ADHD”, Journal of Attention Disorder, vol. 15, no. 7, pp. 583-92.

American Academy of Child and Adolescent Psychiatry (AACAP) 2002, "Practice Parameter for the Use of Stimulant Medications in the Treatment of Children, Adolescent, and Adult", J Am Acad Child Adol Psy, vol. 41.

American Psychiatric Association (APA) 2013, Attention-Deficit/ Hyperactivity Disorder, Diagnostic and Statistical Manual of Mental Disorders fifth edition, American Psychiatric Publishing, USA, pp. 59-65.

Blair, C 2002, "School Readiness-Integrating Cognition and Emotion in a Neurobiological Conceptualization of Children's Functioning at School Entry", American Psychologist, vol. 57, no. 2, pp. 111-27. 
Bonnano, GA \& Mayne, TJ 2001, Emotion: Current Issues and Future Directions, The Guilford Press, New York.

Calkins, S 1997, "Cardiac vagal tone indices of temperamental reactivity and behavioral regulation in young children", Developmental Psychobiology, vol. 21, no. 2, pp. 125-35.

Carmichael, P, Adkins, GI, Hutchins, P, Levy, F, McCormack, J \& Oberklaid, F 1997, Attention deficit hyperactivity disorder, National Health and Medical Research Counsel, Canberra, Australia.

Gray, JR, Braver, TS \& Raichle, ME 2002, Integration of emotion and cognition in the lateral prefrontal cortex, Proceedings of the National Academy of Sciences, USA.

Garber, J, Braafladt, N \& Zeman, J 1991, The regulation of sad affect: An information-processing perspective, The development of emotion regulation and dysregulation, Dodge KA (Ed.), Cambridge University Press, New York.

Hallahan, DP, Lloyd, JW, Kauffman, JM, Weiss, MP \& Martinez, EA 2005, Learning Disabilities: Foundations, Characteristics, and Effective Teaching, Pearson, Boston.

Henriques, G 2016, Social Anxiety: Mapping Its 7 Key Components, diunduh tanggal 14 Juli2017, <https://www.psychologytoday.com/.../201605/social-anxiety-mapping-its-7-keycomponents>

Hoza, B 2007, "Peer Functioning in Children With ADHD”, Journal of Pediatric Psychology, vol. 32, no. 6 , pp. 655-663.

Kamphaus, R 1987, "Conceptual and psychometric issues in the assessment of adaptive behavior", Journal of Special Education, vol. 21, no. 1, pp. 27-35.

Keenan, K \& Shaw, DS 2003, Exploring the Etiology of Antisocial Behavior in the First Years of Life, The Guilford Press, New York.

Kementrian Kesehatan (KEMENKES) R.I 2011, Pedoman Deteksi Dini dan Penanganan Anak dengan Gangguan pemusatan Perhatian dan Hiperaktivitas (GPPH), Kementrian Kesehatan RI.

Maag, JW \& Reid, R 2006, "Depression Among Students with Learning Dissabilities: Assessing the Risk", Journal of Learning Dissabilities, vol. 39, no. 1, pp. 3-10.

Palombo, J 2001, Learning Disorders \& Disorders of the Self in Children \& Adolescents, W.W. Norton \& Co, New York, London.

Pastor, PN \& Reuben, CA 2008, Diagnosed Attention Deficit Hyperactivity Disorder and Learning Disability: United States, 2004-2006, United States, Vital and Health Statistics, vol. 10, no. 237, pp. 1-22.

Pineda, D, Ardila, A, Rosselli, M, Arias, BE, Henao, GC, Gomez, LF, Mejia, SE \& Miranda, ML 1999, "Prevalence of Attention-Deficit/Hyperactivity Disorder Symptoms in 4- to 17-Year-Old 
Children in the General Population", Journal of Abnormal Child Psychology, vol. 27, no. 6, pp. 455-62.

Rush, J 2014, "Working memory, emotion regulation, and effortful control levels in children with attention-deficit hyperactivity disorder", $P h D$ theses, University of Louisville.

Sadock, BJ \& Sadock, VA 2007, Attention Deficit Disorder, Kaplan \& Sadock's Synopsis of Psychiatry: Behavioral Sciences/ Clinical Psychiatry, 10th edition, Lippincott Williams \& Wilkins, Philadelphia, vol. 43, pp. 1207-17.

Saputro, D 2009, ADHD (Attention Deficit / Hyperactivity Disorder), Cetakan Pertama. Jakarta: CV Sagung Seto, pp. 1-85.

Shaw, P, Stringaris, A, Nigg, J \& Leibenluft, E 2014, "Emotional dysregulation and Attention-Deficit/ Hyperactivity Disorder", Am J Psychiatry, vol. 171, no. 3, pp. 276-293.

Smith, TJ \& Adams, G 2006, "The Effect of Comorbid ADHD and Learning Disabilities on Parentreported Behavioral and Academic Outcomes of Children", Spring, vol. 29, pp. 101-12.

Suryani, YE 2010, “Kesulitan belajar”, Magistra, vol. 22, no. 73, pp. 33-47.

Willcutt, EG, Boada, R, Riddle, MW, Chhabildas, N, DeFries, JC \& Pennington, BF 2011, "Colorado Learning Difficulties Questionnaire:Validation of a parent-report screening measure", NIH Public Access-Psychol Assess, vol. 23, no. 3, pp. 778-791, doi:10.1037/a0023290.

Wrong, G 2008, “Emotional Dysregulation in Macklem GL (ed.)”, Practitioner's Guide to Emotion Regulation in School-Aged Children, Springer, pp. 13-24. 